\title{
Peramalan jumlah kedatangan wisatawan mancanegara ke bali menggunakan metode hibrida SSA-WFTS
}

\author{
Nadia Uli Clarissa ${ }^{a, 1}$, Winita Sulandari a,2, ${ }^{*}$, Respatiwulan $^{\mathrm{a}, 3}$ \\ a Program Studi Statistika, Universitas Sebelas Maret, Jl. Ir. Sutami No.36, Kentingan, Kec. Jebres, Kota Surakarta, \\ Jawa Tengah, 57126, Indonesia \\ *2 winita@mipa.uns.ac.id \\ *Correspondent Author
}

KAT A KUNCI

Singular Spectrum Analysis Weighted Fuzzy Time Series Peramalan

\section{KEYWORDS}

Singular Spectrum Analysis Weighted Fuzzy Time Series Forecasting
ABSTRAK

Salah satu provinsi di Indonesia dengan jumlah kunjungan wisatawan mancanegara terbanyak yaitu provinsi Bali. Perlunya peramalan kunjungan wisatawan mancanegara ke Bali yang dapat dijadikan acuan oleh Pemerintah untuk menetapkan strategi dalam memperbaiki kualitas pariwisata di Bali. Metode yang digunakan untuk meramalkan yaitu metode hibrida Singular Spectrum Analysis (SSA) - Weighted Fuzzy Time Series (WFTS). Pemodelan SSA dilakukan untuk menganalisis komponen linear, lalu nilai residu dari model SSA dimodelkan dengan WFTS. Peramalan dilakukan dengan 4 metode yaitu, SSA dengan R-forecasting, SSA-WFTS dengan metode Chen, Yu, Cheng $(\alpha=0,9)$, dan Lee $(c=1,1)$. Keempat metode ini akan dibandingkan untuk memperoleh model terbaik. Hasil peramalan diperoleh nilai MAPE sebesar 14,515\% untuk model SSA R-forecasting, 9,029\% untuk model SSA-WFTS metode Chen, 9,067\% untuk model SSA-WFTS metode $\mathrm{Yu}, 9,125 \%$ untuk model SSA-WFTS metode Cheng $(\alpha=0,9)$, dan $9,028 \%$ untuk model SSA-WFTS metode Lee $(c=1,1)$. Model terbaik diperoleh dengan pemodelan hibrida SSA-WFTS metode Chen dengan nilai MAPE terkecil dibanding model lainnya.

\section{Forecasting the number of international tourist arrivals to Bali using the SSA-WFTS hybrid method}

Bali is one of a province in Indonesia with the most number of foreign tourist arrivals. The result of forecasting the number of tourist arrivals in Bali can be used to improve the quality of tourism in Bali by the government. In this research, hybrid Singular Spectrum Analysis (SSA) - Weighted Fuzzy Time Series (WFTS) method is used for forecasting. The linear component will be modeled by SSA and the residual from the SSA model will be forecasted with WFTS. There are 4 methods for analysis and will be compared to obtain the best model. There are, SSA R-forecasting, SSA-WFTS Chen, SSA-WFTS Yu, SSA-WFTS Cheng $(\alpha=$ $0.9)$, and SSA-WFTS Lee ( $c=1.1)$. The MAPE value obtained from the results of forecasting using the SSA R-forecasting is $14.515 \%$, using the SSA-WFTS Chen is $9.029 \%$, using the SSA-WFTS Yu is $9.067 \%$, using the SSA-WFTS Cheng ( $\alpha=0.9$ ) is $9.125 \%$, and using the SSA-WFTS Lee (c $=1.1$ ) is $9.028 \%$. It shows that forecasting the number of foreign arrivals in Bali using the SSA-WFTS Chen method provides the best forecasting results.

This is an open-access article under the CC-BY-SA license. 


\section{Pendahuluan}

Sektor pariwisata memiliki peran penting terhadap devisa negara, pendapatan daerah, pengembangan wilayah, dan penciptaan lapangan tenaga kerja [1]. Apabila berbicara tentang pariwisata, maka tidak akan jauh kaitannya dengan istilah wisatawan. Wisatawan berdasarkan tempat asalnya dibagi menjadi dua, yaitu wisatawan nusantara dan wisatawan mancanegara (Wisman). Wisatawan mancanegara adalah setiap orang yang melakukan perjalanan ke suatu negara (di luar negara tempat tinggalnya), kurang dari satu tahun, didorong oleh suatu tujuan utama (bisnis, berlibur, atau tujuan pribadi lainnya), selain untuk bekerja pada penduduk negara yang dikunjungi [2]. Indonesia menduduki peringkat keempat dalam kunjungan wisatawan mancanegara ke negara-negara $A S E A N$ dengan jumlah kedatangan yang meningkat tiap tahunnya[3]. Tahun 2019, daya saing pariwisata Indonesia berada pada peringkat 40 dari 140 negara di dunia dengan hasil bahwa Indonesia masih relatif rendah dalam segi lingkungan berkelanjutan, kesehatan dan kebersihan, dan infrastruktur jasa pariwisata [4]. Salah satu provinsi di Indonesia yang menjadi destinasi wisatawan mancanegara adalah Provinsi Bali. Menurut BPS Provinsi Bali pada tahun 2018, 38,8\% wisatawan mancanegara yang mengunjungi Indonesia juga mengunjungi Bali. Hingga tahun 2018, jumlah kunjungan wisatawan mancanegara ke Bali terus meningkat tiap tahunnya [5]. Perlunya peramalan kunjungan wisatawan mancanegara ke Bali yang dapat dijadikan acuan oleh Pemerintah untuk menetapkan strategi dalam memperbaiki kualitas Pariwisata di Bali khususnya dalam segi lingkungan berkelanjutan, kesehatan dan kebersihan, dan infrastruktur jasa pariwisata, seiring dengan bertambahnya jumlah kunjungan wisatawan mancanegara ke Bali tiap tahunnya.

Singular Spectrum Analysis (SSA) merupakan salah satu teknik analisis runtun waktu dan peramalan. SSA bertujuan mendekomposisi deret awal menjadi sejumlahan dari bilangan kecil yang dapat diinterpretasikan seperti trend yang bervariasi lambat, komponen oscillatory dan noise [6]. Beberapa hasil penelitian menunjukkan SSA memberikan hasil yang baik dalam meramalkan data yang memiliki komponen musiman dan tren [7][8][9]. SSA memiliki kekurangan yaitu tidak dapat menangani komponen nonlinear stokastik pada data, sehingga diperlukan suatu cara untuk menangani noise yang mana menunjukkan hubungan nonlinear. Zhang (2001) memperkenalkan metode hibrida model Autoregressive Integrated Moving Average (ARIMA) dan model Artificial Neural Network (ANN) [10]. ARIMA memodelkan hubungan linear pada data dan hubungan nonlinear dimodelkan dengan model $A N N$. Metode hibrida ARIMA-ANN terdiri dari 2 langkah, yaitu pertama dilakukan pemodelan ARIMA untuk menganalisis komponen linear, lalu nilai residu dari model ARIMA akan dimodelkan dengan $A N N$. Metode hibrida ini meningkatkan performa peramalan pada data yang memiliki struktur korelasi linear dan nonlinear. Penanganan komponen nonlinear juga dapat dilakukan dengan model nonlinear lainnya yaitu Weighted Fuzzy Time Series (WFTS).

Weighted Fuzzy Time Series (WFTS) merupakan pengembangan dari Fuzzy Time Series (FTS). Fuzzy Time Series pertama kali diperkenalkan oleh Song dan Chissom (1993) [11], lalu dikembangkan oleh Chen (1996) dengan cara yang lebih sederhana [12], namun metode Chen tidak memperhatikan pengulangan relasi fuzzy dan menganggap semua relasi fuzzy memiliki bobot yang sama, yang mana nilai ramalan yang dihasilkan tidak memuaskan. Yu (2004) mengembangkan metode Chen untuk mengatasi dua permasalahan dalam peramalan Fuzzy Time Series, yaitu pengulangan dan pembobotan dalam relasi fuzzy [13]. Selanjutnya, Cheng (2008) mengembangkan model adaptif dengan nilai ramalan saat $t$ diperoleh dari nilai observasi pada saat $t-1$ dijumlahkan dengan bobot kesalahan peramalan terakhir. Lalu, Lee dan Suhartono (2010), mengembangkan metode Yu dengan mengatur bobot dari relasi fuzzy sebagai fungsi exponential growth [14].

Beberapa penelitian menggabungkan metode lain dengan metode WFTS, diantaranya dengan metode SSA-FLR [15], [16], dan dengan metode Winter [17]. Metode hibrida SSA-FLRWFTS memberikan hasil yang lebih baik dibandingkan metode SSA-FLR [15]. Selain itu, peramalan jumlah kedatangan wisatawan mancanegara ke Bali menggunakan metode hibrida 
Winter-WFTS memberikan hasil peramalan yang lebih baik dibandingkan metode dekomposisi, Winter, dan ARIMA [17].

Berdasarkan penjelasan di atas, penelitian ini bertujuan memperoleh model terbaik dan mendapatkan hasil ramalan jumlah kedatangan wisatawan mancanegara ke Bali dengan menggunakan metode hibrida SSA-WFTS.

\section{Metode}

Data yang digunakan dalam penelitian ini adalah jumlah kedatangan wisatawan mancanegara ke Bali tahun 2009-2019. Data merupakan data sekunder yang diperoleh dari laman resmi Badan Pusat Statistik (BPS) Provinsi Bali yaitu https://bali.bps.go.id/ dan merupakan data bulanan. Data akan dibagi menjadi dua, yaitu data in-sample dan data outsample. Data in-sample yaitu data pada tahun 2009-2018 sedangkan data out-sample yaitu data pada tahun 2019. Analisis dilakukan menggunakan metode hibrida SSA-WFTS. Pada penelitian ini, metode hibrida SSA-WFTS dibagi menjadi 2 langkah, langkah pertama yaitu SSA dengan $R$ forecasting untuk memodelkan komponen deterministik dan langkah kedua yaitu menggabungkan SSA dengan WFTS, yang mana algoritma WFTS dijalankan untuk memodelkan komponen nonlinear stokastik dari nilai residu model $S S A$. Adapun langkah-langkah hibrida SSA-WFTS adalah sebagai berikut :

1) Pemodelan dan peramalan menggunakan metode SSA dengan $R$-forecasting [18]:

a) Decomposition

\section{i) Embedding}

Tahap embedding mengubah deret waktu menjadi matriks lintasan (Trajectory Matrix) dengan mentransformasi data yang berdimensi satu (vektor) menjadi data yang multidimensional (matriks). Didefinisikan $L$ merupakan panjang jendela (windows length) dengan $2<L<N / 2$ dan $K=N-L+1$, maka akan membentuk matriks sebagai berikut:

$$
\boldsymbol{X}=\left(x_{i j}\right)_{i, j=1}^{L, K}=\left[\begin{array}{cccc}
f_{0} & f_{1} & \cdots & f_{K-1} \\
f_{1} & f_{2} & \cdots & f_{K} \\
\vdots & \vdots & \ddots & \vdots \\
f_{L-1} & f_{L} & \cdots & f_{N-1}
\end{array}\right]
$$

Matriks $\boldsymbol{X}$ disebut matriks Hankel, yang mana semua elemen anti-diagonalnya bernilai sama.

ii) Singular Value Decomposition (SVD)

Pada tahap ini, dilakukan singular value decomposition pada matriks (1). Definisikan $\mathbf{S}=\boldsymbol{X} \boldsymbol{X}^{\boldsymbol{T}}$ dan eigenvalues dari $\mathbf{S}$ adalah $\lambda_{1, \ldots .}, \lambda_{L}$. Eigenvectors dari tiap eigenvalues yaitu $U_{1}, \ldots, U_{L}$. Selanjutnya, $V_{i}=\boldsymbol{X}^{\boldsymbol{T}} U_{i} / \sqrt{\lambda_{i}}$, maka $S V D$ dari matriks trajektori $\boldsymbol{X}$ dapat ditulis dalam persamaan (2).

$$
\boldsymbol{X}=\boldsymbol{X}_{1}+\cdots+\boldsymbol{X}_{d}
$$

dengan $\boldsymbol{X}_{i}=\sqrt{\lambda_{i}} U_{i} V_{i}^{T}$ untuk $i=1, \ldots, d, d=\max \left\{i: \lambda_{i}>0\right\}$. Kumpulan $\left(\sqrt{\lambda_{i}}, U_{i}, V_{i}^{T}\right)$ dapat disebut dengan eigentriple ke-i dari $S V D$ dan $\boldsymbol{X}_{\mathrm{i}}$ disebut principal component (PC) [19].

b) Reconstruction

\section{i) Grouping}

Pada tahap grouping, matriks dikelompokkan ke dalam subkelompok berdasarkan pola pembentuk data deret waktu yakni trend, seasonal, dan noise. Tahap grouping pada langkah rekonstruksi merupakan partisi himpunan dari indeks $\{1, \ldots, d\}$ menjadi $m$ disjoint subset $I_{1}, \ldots, I_{m}$. Jika $\boldsymbol{I}=\left\{i_{1}, \ldots, i_{p}\right\}$, maka resultant matrix $\boldsymbol{X}_{I}$ yang dapat didefinisikan sebagai $\boldsymbol{X}_{I}=\boldsymbol{X}_{i 1}+\boldsymbol{X}_{i 2} \ldots+\boldsymbol{X}_{i p}$, berkorespondensi dengan $\boldsymbol{I}=$ $\left\{I_{1}, \ldots, I_{m}\right\}$. Maka, $\boldsymbol{X}=\boldsymbol{X}_{1}+\boldsymbol{X}_{2}+\cdots+\boldsymbol{X}_{d}$, dapat ditulis menjadi persamaan (3). 


$$
\boldsymbol{X}=\boldsymbol{X}_{I 1}+\boldsymbol{X}_{I 2} \ldots+\boldsymbol{X}_{I m}
$$

Prosedur untuk memilih set $I_{1}, \ldots, I_{m}$ disebut eigentriple grouping.

\section{ii) Diagonal Averaging}

Pada tahap ini, tiap matriks dari tahap grouping menjadi deret baru dengan panjang $N$. Misal $\mathbf{Y}$ adalah matriks berukuran $L \times K$ dengan elemen $y_{i j}$. Dengan $1 \leq i \leq$ $L$ dan $1 \leq j \leq K$. Tentukan $L^{*}=\min (L, K), K^{*}=\max (L, K), N=L+K-1$, dan $y_{i j}^{*}=y_{i j}$ jika $L>K$ dan $y_{i j}^{*}=y_{i j}$ lainnya. Matriks $\mathbf{Y}$ ditransformasikan ke dalam bentuk deret kembali kembali, $f_{0}, \ldots, f_{N-1}$ menggunakan metode diagonal averaging dengan menggunakan persamaan berikut :

$$
\tilde{f}_{k}= \begin{cases}\frac{1}{k+1} \sum_{m=1}^{k+1} y_{m, k-m+2}^{*} & \text { untuk } 1 \leq k<L^{*}-1, \\ \frac{1}{L^{*}} \sum_{m=1}^{L^{*}} y_{m, k-m+2}^{*} & \text { untuk } L^{*}-1 \leq k<K^{*}, \\ \frac{1}{N-k} \sum_{m=k-K^{*}+2}^{N-K^{*}+1} y_{m, k-m+2}^{*} & \text { untuk } K^{*} \leq k<N .\end{cases}
$$

Diagonal averaging (4) diterapkan pada resultant matrix $\boldsymbol{X}_{I_{k}}$ pada persamaan (3), sehingga $\mathbf{X}_{I_{k}}$ akan membentuk deret rekontruksi $\tilde{F}^{(k)}=\left(\tilde{f}_{0}^{(k)}, \ldots, \tilde{f}_{N-1}^{(k)}\right)$. Oleh karena itu, deret asli $f_{0}, f_{1}, \ldots, f_{N-1}$ akan menjadi jumlah dari $m$ deret sebagai berikut:

$$
f_{n}=\sum_{k=1}^{m} \tilde{f}_{n}^{(k)},(n=0,1, \ldots, N-1)
$$

2) Peramalan menggunakan algoritma $R$-forecasting

a) Deret waktu $F_{N+M}=\left(f_{0}, \ldots, f_{N+M-1}\right)$ didefinisikan dengan,

$$
\hat{f}_{i}=\left\{\begin{array}{cl}
\tilde{f}_{i} & \text { untuk } i=0, \ldots, N-1, \\
\sum_{j=1}^{L-1} a_{j} f_{i-j} & \text { untuk } i=N, \ldots, N+M-1,
\end{array}\right.
$$

dengan vektor dari koefisien $\mathcal{R}=\left(a_{L-1}, \ldots, a_{1}\right)^{\mathrm{T}}$ yang dapat diekspresikan sebagai,

$$
\mathcal{R}=\frac{1}{1-v^{2}} \sum_{i=1}^{r} \pi_{i} U_{i}^{\nabla}
$$

Definisikan $U_{i}^{\nabla}$ adalah vektor komponen $L$-1 pertama dari eigenvector $U_{i}$ dan $v^{2}=$ $\pi_{1}^{2}+\cdots+\pi_{r}^{2}$. Dengan $\pi_{i}$ adalah komponen terakhir dari vektor $U_{i}$, untuk $i=1, \ldots, r$.

b) Angka-angka $\hat{f}_{N}, \ldots, \hat{f}_{N+M-1}$ membentuk $M$ langkah kedepan dari peramalan $S S A$.

3) Meramalkan nilai residu dari model SSA dengan WFTS

a) Metode Chen

Algoritma metode Chen adalah sebagai berikut [12]:

i) Mendefinisikan semesta pembicaraan (universe of discourse) dari data historis,

$$
U=[\text { Dmin - D1, Dmax - D2], }
$$

dengan Dmin dan Dmax adalah data minimum dan maksimum dan D1 dan D2 adalah bilangan positif.

ii) Membagi semesta pembicaraan ke dalam interval yang sama, $U=\left\{u_{1}, u_{2}, \ldots, u_{m}\right\}$. 
iii) Menentukan himpunan fuzzy pada $U$. Melakukan fuzzifikasi pada data historis yang diamati. Misal $A_{1}, A_{2}, \ldots, A_{i}$ adalah himpunan fuzzy yang mempunyai nilai linguistik dari suatu variabel linguistik. Pendefinisian himpunan fuzzy $A_{1}, A_{2}, \ldots, A_{i}$ pada himpunan semesta $U$ sebagai berikut:

$$
\begin{aligned}
& A_{1}=\frac{a_{11}}{u_{1}}+\frac{a_{12}}{u_{2}}+\cdots+\frac{a_{1 m}}{u_{m}}, \\
& A_{2}=\frac{a_{21}}{u_{1}}+\frac{a_{22}}{u_{2}}+\cdots+\frac{a_{2 m}}{u_{m}}, \\
& A_{k}=\frac{a_{k 1}}{u_{1}}+\frac{a_{k 2}}{u_{2}}+\cdots+\frac{a_{k m}}{u_{m}},
\end{aligned}
$$

dengan nilai $a_{i j}$ mempunyai range [0,1], $1 \leq i \leq k$ dan $1 \leq j \leq m$. Nilai dari $a_{i j}$ menandakan derajat keanggotaan dari $u_{j}$ dalam himpunan fuzzy $A_{i}$. Apabila suatu data mempunyai nilai derajat keanggotaan maksimum pada himpunan fuzzy $A_{k}$, maka data tersebut masuk ke dalam himpunan fuzzy $A_{k}$ atau variabel linguistik $A_{k}$.

iv) Menentukan Fuzzy Logical Relationship (FLR). Dua himpunan fuzzy berturut-turut $A_{i}(t-p)$ dan $A_{j}(t)$ dapat dibentuk menjadi FLR $\left(A_{i} \rightarrow A_{j}\right) . A_{i}$ disebut sebagai Left Hand Sides (LHS) dan $A_{j}$ disebut dengan Right Hand Sides (RHS).

v) Menentukan Fuzzy Logical Relationship Group (FLRG) untuk semua FLR berdasarkan LHS yang sama. Contoh, jika FLR berbentuk $A_{1} \rightarrow A_{2}, A_{1} \rightarrow A_{1}, A_{1} \rightarrow$ $A_{2}, A_{1} \rightarrow A_{3}$, maka $F L R G$ yang terbentuk ialah $A_{1} \rightarrow A_{1}, A_{2}, A_{3}$.

vi) Melakukan peramalan. Jika $F(t-1)=A_{1}$, maka terdapat beberapa aturan sebagai berikut yang meliputi :

(1) Jika tidak terdapat $F L R$ dari $A_{i},\left(A_{1} \rightarrow \#\right)$, maka $F(t)=A_{i}$.

(2) Jika hanya terdapat satu $F L R,\left(A_{1} \rightarrow A_{j}\right)$, maka $F(t)=A_{j}$.

(3) Jika terdapat banyak $F L R\left(A_{j 1}, A_{j 2}, \ldots, A_{j k}\right)$, maka $F(t)=A_{j 1}, A_{j 2}, \ldots, A_{j k}$.

vii) Defuzzifikasi. Misalkan $F(t)=A_{j 1}, A_{j 2}, \ldots, A_{j k}$, maka $\widehat{y}=\frac{\sum_{p=1}^{k} m_{j p}}{k}$, dengan $\widehat{y}(t)$ merupakan defuzzifikasi dan $m_{j p}$ adalah nilai tengah dari $A_{j p}$.

b) Metode Yu

Algoritma Yu adalah sebagai berikut [13]:

i) Mendefinisikan semesta pembicaraan (universe of discourse) dari data historis.

ii) Membagi semesta pembicaraan ke dalam interval yang sama, $U=\left\{u_{1}, u_{2}, \ldots, u_{m}\right\}$.

iii) Menentukan himpunan fuzzy pada $U$ dan melakukan fuzzifikasi pada data historis yang diamati.

iv) Menentukan Fuzzy Logical Relationship (FLR).

v) Menentukan Fuzzy Logical Relationship Group (FLRG) untuk semua FLR berdasarkan $L H S$ yang sama sesuai urutan waktu. Contoh, jika FLR berbentuk $A_{1} \rightarrow$ $A_{2}, A_{1} \rightarrow A_{1}, A_{1} \rightarrow A_{2}, A_{1} \rightarrow A_{3}$, maka FLRG yang terbentuk ialah $A_{1} \rightarrow$ $A_{2}, A_{1}, A_{2}, A_{3}$.

vi) Melakukan peramalan sama dengan metode Chen.

vii) Defuzzifikasi. Misalkan $F(t)=A_{j 1}, A_{j 2}, \ldots, A_{j k}$, maka matriks yang didefuzzifikasi yaitu matriks nilai titik tengah dari $A_{j 1}, A_{j 2}, \ldots, A_{j k}$ yang dapat ditulis dengan,

$$
M(t)=\left[m_{j 1}, m_{j 2}, \ldots, m_{j k}\right],
$$

dengan $M(t)$ merupakan nilai defuzzifikasi peramalan dari $F(t)$.

viii) Menghitung bobot. Pembobot untuk $F(t)=A_{j 1}, A_{j 2}, \ldots, A_{j k}$ ialah dengan $w^{\prime}{ }_{1}, w_{2}^{\prime}, \ldots, w^{\prime}{ }_{k}$ dengan $w_{i}^{\prime}=\frac{w_{i}}{\sum_{h=1}^{k} w_{h}}$, dengan $w_{1}=1, w_{i}=w_{i-1}+1$ untuk $2 \leq i \leq$ $k$, dan $w_{h}$ adalah bobot untuk $A_{j h}$. Sehingga matriks pembobot dapat ditulis sebagai, 


$$
W(t)=\left[w^{\prime}{ }_{1}, w^{\prime}{ }_{2}, \ldots, w^{\prime}{ }_{k}\right]=\left[\frac{1}{\sum_{h=1}^{k} w_{h}}, \frac{2}{\sum_{h=1}^{k} w_{h}}, \ldots, \frac{k}{\sum_{h=1}^{k} w_{h}}\right] .
$$

ix) Menghitung nilai ramalan akhir. Nilai ramalan akhir diperoleh dari perkalian matriks yang didefuzzifikasi dan tranpos dari matriks pembobot.

$$
\begin{gathered}
\hat{F}(t)=M(t) \times w(t)^{T} \\
\hat{F}(t)=\left[m_{j 1}, m_{j 2}, \ldots, m_{j k}\right] \times\left[\frac{1}{\sum_{h=1}^{k} w_{h}}, \frac{2}{\sum_{h=1}^{k} w_{h}}, \ldots, \frac{k}{\sum_{h=1}^{k} w_{h}}\right]^{\mathrm{T}},
\end{gathered}
$$

dengan $\times$ merupakan operator perkalian matriks.

c) Metode Cheng

Algoritma metode Cheng adalah sebagai berikut [20]:

i) Mendefinisikan semesta pembicaraan (universe of discourse) dari data historis.

ii) Membagi semesta pembicaraan ke dalam interval yang sama, $U=\left\{u_{1}, u_{2}, \ldots, u_{m}\right\}$.

iii) Melakukan fuzzifikasi.

iv) Menentukan Fuzzy Logical Relationship (FLR).

v) Menentukan Fuzzy Logical Relationship Group (FLRG) untuk semua FLR berdasarkan $L H S$ yang sama sesuai urutan waktu. Contoh, apabila FLR berbentuk $A_{1} \rightarrow A_{2}, A_{1} \rightarrow A_{1}, A_{1} \rightarrow A_{2}, A_{1} \rightarrow A_{3}$, maka FLRG yang terbentuk ialah $A_{1} \rightarrow$ $A_{2}, A_{1}, A_{2}, A_{3}$ dengan matriks pembobot $w(t)=[w 1, \ldots, w 4]=[1,1,2,1]$.

vi) Menghitung nilai ramalan dengan $F(t)=L_{d f}(t-1) \cdot W_{n}(t-1)$, dengan $L_{d f}(t-$ 1) adalah matriks defuzzifikasi dan $W_{n}(t-1)$ adalah matriks pembobot. Sebagai contoh, jika $F(t)$ adalah $A_{2}, A_{3}, A_{1}, A_{2}$, maka nilai ramalan ialah,

$$
F(t)=\left[m_{2}, m_{3}, m_{1}, m_{2}\right] \times\left[\frac{1}{1+1+2+1}, \frac{1}{5}, \frac{1}{5}, \frac{2}{5}\right]^{\mathrm{T}} .
$$

vii) Menghitung nilai ramalan akhir dengan $\hat{y}(t)=y(t-1)+(\alpha \times[F(t)-y(t-1)]$, dengan $y(t-1)$ adalah nilai pengamatan pada saat $t-1$ dan $\alpha$ adalah parameter pembobot.

d) Metode Lee

Algoritma metode Lee adalah sebagai berikut [14]:

i) Mendefinisikan semesta pembicaraan (universe of discourse) dari data historis.

ii) Membagi semesta pembicaraan ke dalam interval yang sama, $U=\left\{u_{1}, u_{2}, \ldots, u_{m}\right\}$.

iii) Melakukan fuzzifikasi.

iv) Menentukan Fuzzy Logical Relationship (FLR)

v) Menentukan Fuzzy Logical Relationship Group (FLRG) untuk semua FLR berdasarkan LHS yang sama. Contoh, jika FLR berbentuk $A_{1} \rightarrow A_{2}, A_{1} \rightarrow A_{1}, A_{1} \rightarrow$ $A_{2}, A_{1} \rightarrow A_{3}$, maka FLRG yang terbentuk ialah $A_{1} \rightarrow A_{2}, A_{1}, A_{2}, A_{3}$.

vi) Melakukan peramalan sama dengan metode Chen.

vii) Defuzzifikasi. Misalkan $F(t)=A_{j 1}, A_{j 2}, \ldots, A_{j k}$, maka matriks yang didefuzzifikasi yaitu matriks nilai titik tengah dari $A_{j 1}, A_{j 2}, \ldots, A_{j k}$ yang dapat ditulis dengan,

$$
M(t)=\left[m_{j 1}, m_{j 2}, \ldots, m_{j k}\right],
$$

dengan $M(t)$ merupakan nilai defuzzifikasi peramalan dari $F(t)$.

viii) Menghitung bobot. Pembobot untuk $F(t)=A_{j 1}, A_{j 2}, \ldots, A_{j k}$ ialah dengan $w_{1}^{\prime}, w_{2}^{\prime}{ }_{2}, \ldots, w^{\prime}{ }_{k}$ dengan $w^{\prime}{ }_{i}=\frac{w_{i}}{\sum_{h=1}^{k} w_{h}}, w_{1}=1, w_{i}=c^{i-1}$ untuk $2 \leq i \leq k, c \geq 1$ dan $w_{h}$ adalah bobot untuk $A_{j \mathrm{~h}}$. Sehingga matriks pembobot dapat ditulis sebagai,

$$
W(t)=\left[{w^{\prime}}_{1}, w^{\prime}{ }_{2}, \ldots, w^{\prime}{ }_{k}\right]=\left[\frac{1}{\sum_{h=1}^{k} w_{h}}, \frac{c}{\sum_{h=1}^{k} w_{h}}, \ldots, \frac{c^{k-1}}{\sum_{h=1}^{k} w_{h}}\right] .
$$

ix) Menghitung nilai ramalan akhir. Nilai ramalan akhir diperoleh dari perkalian matriks yang didefuzzifikasi dan tranpos dari matriks pembobot.

$$
\hat{F}(t)=M(t) \times w(t)^{T}
$$




$$
\hat{F}(t)=\left[m_{j 1}, m_{j 2}, \ldots, m_{j k}\right] \times\left[\frac{1}{\sum_{h=1}^{k} w_{h}}, \frac{c}{\sum_{h=1}^{k} w_{h}}, \ldots, \frac{c^{k-1}}{\sum_{h=1}^{k} w_{h}}\right]^{\mathrm{T}},
$$

dengan $\times$ merupakan operator perkalian matriks.

4) Menghitung nilai ramalan akhir dengan menjumlahkan nilai ramalan SSA dengan $R$ forecasting dan nilai ramalan residu dari peramalan menggunakan WFTS.

5) Menghitung MAPE dan menentukan model terbaik.

\section{Hasil dan pembahasan}

\section{Identifikasi Data}

Plot data jumlah kedatangan wisatawan mancanegara ke Bali pada tahun 2009-2018 ditunjukkan pada Gambar 1. Plot menunjukkan bahwa data memiliki pola tren dan musiman. Pola kunjungan menunjukkan pola yang hampir sama tiap tahunnya. Pada awal tahun, jumlah kedatangan cenderung rendah, lalu puncak kedatangan tertinggi terjadi pada bulan-bulan triwulan ketiga, seperti bulan Juli dan Agustus. Bulan selanjutnya mengalami penurunan, lalu meningkat kembali di akhir tahun dikarenakan libur akhir tahun. Pada bulan Agustus sampai Desember 2017, jumlah kedatangan wisman mengalami penurunan terus menerus dikarenakan bencana erupsi Gunung Agung yang dimulai sejak bulan Agustus 2017. Jumlah kedatangan wisman yang berangsur-angsur mengalami penurunan hingga mencapai titik terendah di Bulan Desember, cukup berimbas ke bulan Januari 2018 terkait dengan pemberlakuan travel advice hingga Januari 2018 [5].

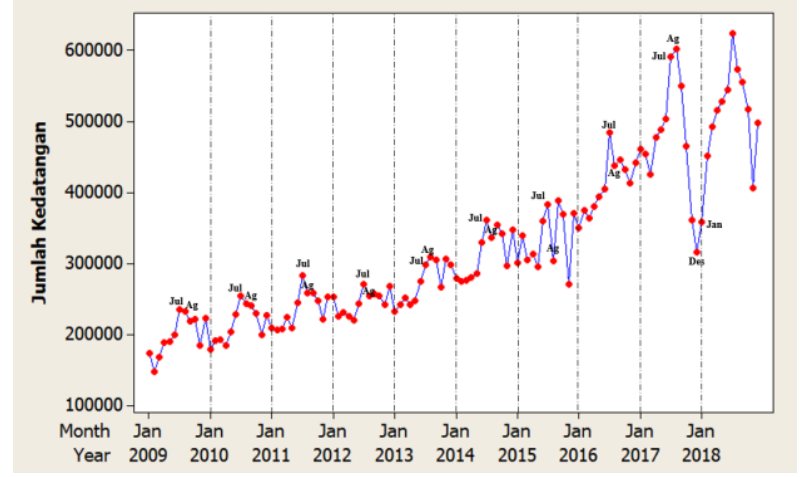

Gambar 1. Plot Jumlah Kedatangan Wisman ke Bali

Peramalan dengan Metode SSA-WFTS

1) Pemodelan $S S A$

a) Decomposition

\section{i) Embedding}

Pada penelitian ini, ditentukan nilai windows length sebesar $59(L=59)$, maka $K=120-59+1=60$. Matriks lintasan $L \times K$ yang terbentuk sebagai berikut:

$$
\boldsymbol{X}=\left(x_{i j}\right)_{i, j=1}^{59,60}=\left[\begin{array}{cccc}
174541 & 147704 & \cdots & 299013 \\
147704 & 168205 & \cdots & 279257 \\
\vdots & \vdots & \ddots & \vdots \\
307276 & 299013 & \cdots & 498819
\end{array}\right]
$$

ii) Singular Value Decomposition (SVD)

Plot yang terbentuk dari 50 singular values jumlah kedatangan wisatawan mancanegara ke Bali dapat dilihat pada Gambar 2. 


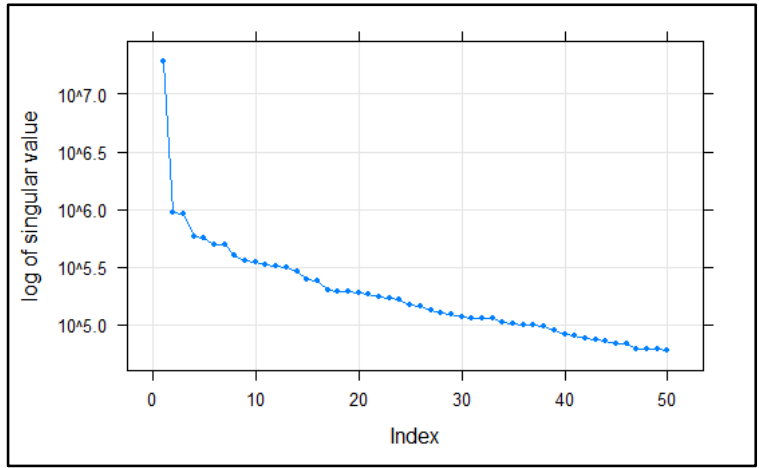

Gambar 2. Plot dari 50 Singular Values Jumlah Kedatangan

Wisatawan Mancanegara ke Bali

Effect grouping ( $r$ ) digunakan untuk membantasi nilai eigentriples yang akan digunakan untuk mengidentifikasi komponen tren dan musiman. Nilai $r$ ditentukan berdasarkan jumlah eigentriples yang tidak menunjukkan noise pada plot singular value. Rentetan singular values yang menurun secara perlahan pada plot singular value menunjukkan komponen noise [21]. Gambar 2 menunjukkan bahwa pergerakan antar singular values mulai melambat setelah eigentriple ke-7, maka eigentriple ke-1 sampai ke-7 merupakan komponen tren dan musiman. Eigentriple ke-8 sampai ke-50 akan digabung lalu dikategorikan sebagai komponen noise.

b) Reconstruction

\section{i) Grouping}

Pengelompokan eingentriple akan dibagi menjadi komponen tren dan komponen musiman. Plot dari seri yang sudah direkonstruksi dapat digunakan untuk mengidentifikasi eigentriple yang memiliki komponen tren dan komponen musiman. Pengelompokan eigentriple dapat dilihat dari kemiripan singular value dari masingmasing eigentriple. Berdasarkan Gambar 3, pengelompokan dibagi menjadi 4 bagian yaitu tren, musiman 1, musiman 2, dan musiman 3. Tren terdiri dari eigentriple ke-1. Musiman 1 terdiri dari eigentriple ke-2 dan ke-3. Eigentriple ke-4 dan ke-5 dikelompokkan menjadi musiman 2. Lalu, musiman 3 terdiri dari eigentriple ke- 6 dan ke-7. Terakhir, noise terdiri dari eigentriple ke-8 sampai ke-59 yang dapat dilihat pada Gambar 4.

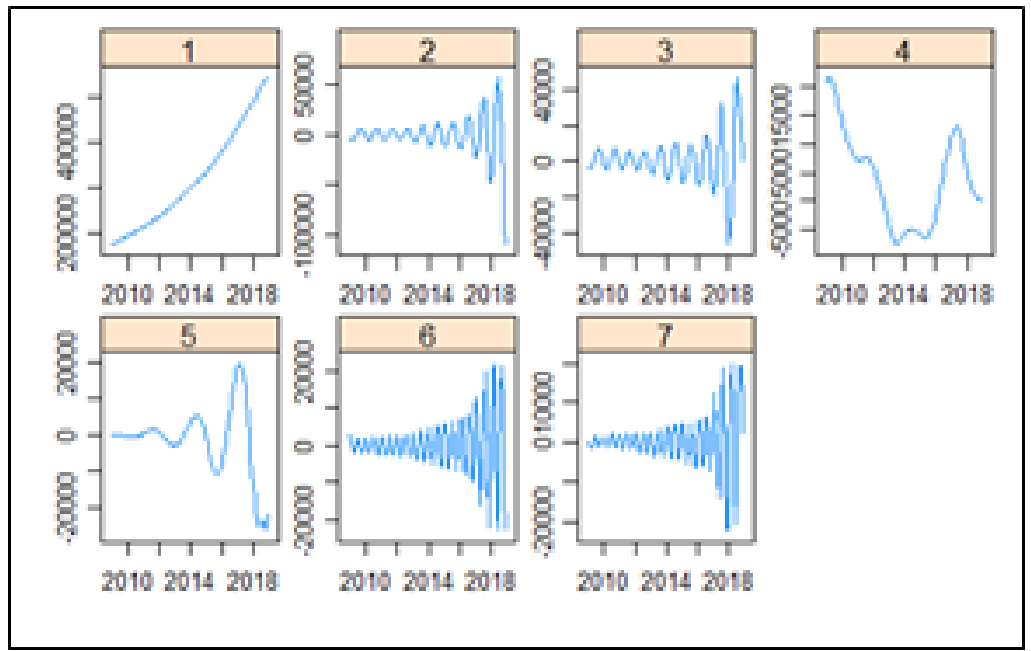

Gambar 3. Plot dari deret jumlah kedatangan wisatawan ke bali yang sudah direkonstruksi 


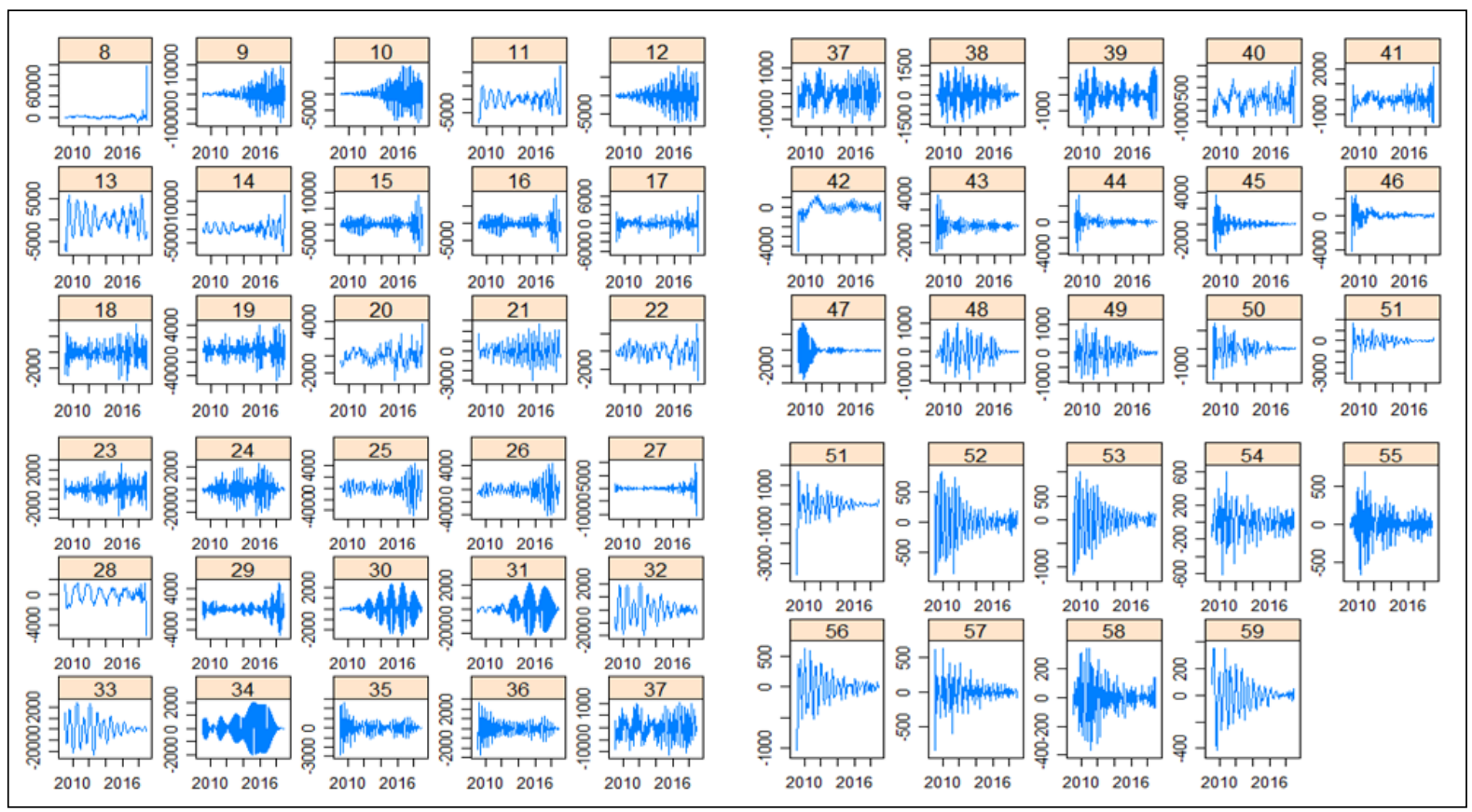

Gambar 4. Plot dari yang sudah direkonstruksi dan dikelompokkan ke dalam Noise

ii) Diagonal Averaging

Deret yang sudah direkonstruksi yang berasal dari hasil diagonal averaging ditampilkan pada Tabel 1 .

Tabel 1. Hasil Diagonal Averaging deret Jumlah Kedatangan Wisatawan Mancanegara ke Bali yang sudah dikelompokkan

\begin{tabular}{|c|c|c|c|c|c|c|c|c|}
\hline \multirow[b]{2}{*}{$\begin{array}{c}\text { Tahu } \\
n\end{array}$} & \multirow[b]{2}{*}{$\begin{array}{c}\text { Bula } \\
n\end{array}$} & \multirow[b]{2}{*}{$\begin{array}{c}\text { Data } \\
\text { Asli }\end{array}$} & \multicolumn{4}{|c|}{ Rekonstruksi } & \multirow{2}{*}{$\begin{array}{c}\text { Diagonal } \\
\text { Averagin } \\
\quad g \\
\end{array}$} & \multirow[b]{2}{*}{ Residu } \\
\hline & & & Tren & $\begin{array}{c}\text { Musima } \\
\quad \text { n } 1\end{array}$ & $\begin{array}{c}\text { Musima } \\
\quad \text { n } 2\end{array}$ & $\begin{array}{c}\text { Musima } \\
\quad \text { n } 3\end{array}$ & & \\
\hline 2009 & Jan & $\begin{array}{c}17454 \\
1\end{array}$ & $\begin{array}{c}174756 \\
8\end{array}$ & $\begin{array}{c}- \\
6579,82\end{array}$ & $\begin{array}{c}21264,4 \\
2\end{array}$ & $\begin{array}{c}2975,90 \\
7\end{array}$ & 192417,3 & 17876,3 \\
\hline 2009 & Feb & $\begin{array}{c}14770 \\
4\end{array}$ & $\begin{array}{c}\text { 176111 } \\
4\end{array}$ & $\begin{array}{c}- \\
8287,27\end{array}$ & $\begin{array}{c}21191,3 \\
7\end{array}$ & $\begin{array}{c}231.917 \\
9\end{array}$ & 189247,4 & $\begin{array}{c}- \\
41543,4\end{array}$ \\
\hline 2009 & Mar & $\begin{array}{c}16820 \\
5\end{array}$ & $\begin{array}{c}177528 \\
7\end{array}$ & $\begin{array}{c}- \\
8004,53\end{array}$ & 21534,8 & $-2847,4$ & 188211,6 & 20006,6 \\
\hline $\begin{array}{c}\cdots \\
2018\end{array}$ & $\begin{array}{c}\cdots \\
\text { Des }\end{array}$ & $\begin{array}{c}\ldots \\
49881 \\
9\end{array}$ & $\begin{array}{c}\ldots \\
542010 \\
2\end{array}$ & $\begin{array}{c}\cdots \\
-108090\end{array}$ & $\begin{array}{c}\cdots \\
- \\
22136,5\end{array}$ & $\begin{array}{c}\cdots \\
- \\
20363,7\end{array}$ & $\begin{array}{c}\cdots \\
391419,7\end{array}$ & $\begin{array}{c}\ldots \\
107399, \\
3\end{array}$ \\
\hline
\end{tabular}

2) Peramalan dengan R-forecasting

Hasil peramalan data out-sample dengan metode SSA dengan R-forecasting ditunjukkan pada Tabel 2. Peramalan jumlah kunjungan wisatawan mancanegara ke Bali menggunakan metode SSA dengan $R$-forecasting menghasilkan nilai MAPE sebesar 14,515\%. 
Tabel 2. Hasil Peramalan dengan metode $S S A$ dengan R-forecasting

\begin{tabular}{cccc}
\hline Tahun & Bulan & Data Asli & Hasil Ramalan \\
\hline 2019 & Jan & 455570 & 396720 \\
2019 & Feb & 437456 & 462990 \\
$\ldots$ & $\ldots$ & $\ldots$ & $\ldots$ \\
2019 & Des & 552403 & 462683 \\
\hline MAPE & & & $\mathbf{1 4 , 5 1 5 \%}$ \\
\hline
\end{tabular}

Meramalkan nilai residu dari model SSA dengan WFTS

a) Menentukan Universe of Discourse

Rentang nilai universe of discourse ditentukan dari rentang -190000 sampai 110000, maka diperoleh,

$$
U=[-190000,110000]
$$

b) Membagi Semesta Pembicaraan ke dalam Interval yang Sama dan Menentukan Himpunan Fuzzy pada $U$

Interval ditentukan sebesar 5000, sehingga semesta pembicaraan terbagi menjadi 60 interval $\left(u_{1}, u_{2}, u_{3}, \ldots, u_{60}\right)$. Selanjutnya, himpunan fuzzy ditentukan dengan menambahkan variabel linguistik $A_{1}, A_{2}, \ldots, A_{60}$ pada setiap $u_{1}, u_{2}, u_{3}, \ldots, u_{60}$, yang ditampilkan pada Tabel 3.

Tabel 3. Hasil Pembagian Semesta ke dalam Interval yang Sama

\begin{tabular}{ccccc}
\hline Semesta & Min & Mean & Max & $\begin{array}{c}\text { Himpunan } \\
\text { Fuzzy }\end{array}$ \\
\hline $\mathrm{u}_{1}$ & -190000 & -187500 & -185000 & $\mathrm{~A}_{1}$ \\
$\mathrm{u}_{2}$ & -185000 & -182500 & -180000 & $\mathrm{~A}_{2}$ \\
$\mathrm{u}_{3}$ & -180000 & -177500 & -175000 & $\mathrm{~A}_{3}$ \\
$\ldots$ & $\ldots$ & $\ldots$ & $\ldots$ & $\ldots$ \\
$\mathrm{u}_{60}$ & 105000 & 107500 & 110000 & $\mathrm{~A}_{60}$ \\
\hline
\end{tabular}

c) Melakukan Fuzzifikasi

Fuzzifikasi merupakan proses penentuan data aktual ke dalam himpunan fuzzy. Hasil fuzzifikasi ditampilkan pada Tabel 4.

Tabel 4. Hasil Fuzzifikasi

\begin{tabular}{ccc}
\hline No. & $\begin{array}{c}\text { Residu dari } \\
\text { Model SSA }\end{array}$ & $\begin{array}{c}\text { Himpunan } \\
\text { Fuzzy }\end{array}$ \\
\hline 1 & $-17876,3$ & $A_{35}$ \\
2 & $-41543,4$ & $A_{30}$ \\
3 & $-20006,6$ & $A_{34}$ \\
$\ldots$ & $\ldots$ & $\ldots$ \\
120 & 107399,3 & $A_{60}$ \\
\hline
\end{tabular}

d) Menentukan Fuzzy Logical Relationship (FLR) dan Fuzzy Logical Relationship Group (FLRG)

Hasil dari Fuzzy Logical Relationship (FLR) ditampilkan pada Tabel 5. 
Tabel 5. Fuzzy Logical Relationsip (FLR)

$$
\begin{aligned}
A_{35} & \rightarrow A_{30} \\
A_{30} & \rightarrow A_{34} \\
A_{34} & \rightarrow A_{38} \\
A_{38} & \rightarrow A_{37} \\
& \cdots \\
A_{36} & \rightarrow A_{60} \\
A_{60} & \rightarrow \#
\end{aligned}
$$

FLRG akan dibagi menjadi 2 macam. Pertama, FLRG dengan tidak memperhatikan pengulangan relasi fuzzy yang akan digunakan untuk metode Chen. Kedua, yaitu FLRG dengan memperhatikan pengulangan relasi fuzzy untuk metode Yu, Cheng, dan Lee. Tabel 6 menunjukkan hasil FLRG dengan tidak memperhatikan pengulangan dan peramalannya. Tabel 7 menunjukkan hasil FLRG dengan memperhatikan pengulangan dan peramalannya.

Tabel 6. $F L R G$ dengan tidak Memperhatikan Pengulangan dan Peramalannya

\begin{tabular}{cc}
\hline $\boldsymbol{F L} \boldsymbol{R} \boldsymbol{G}$ & $\boldsymbol{F}(\boldsymbol{t})$ \\
\hline $\mathrm{A}_{24} \rightarrow \mathrm{A}_{44}$ & $\mathrm{~A}_{44}$ \\
$\mathrm{~A}_{26} \rightarrow \mathrm{A}_{45}$ & $\mathrm{~A}_{45}$ \\
$\mathrm{~A}_{30} \rightarrow \mathrm{A}_{34}$ & $\mathrm{~A}_{34}$ \\
$\mathrm{~A}_{32} \rightarrow \mathrm{A}_{37}, \mathrm{~A}_{34}$ & $\mathrm{~A}_{37}, \mathrm{~A}_{34}$ \\
$\mathrm{~A}_{33} \rightarrow \mathrm{A}_{41}, \mathrm{~A}_{37}, \mathrm{~A}_{42}, \mathrm{~A}_{35}$ & $\mathrm{~A}_{41}, \mathrm{~A}_{37}, \mathrm{~A}_{42}, \mathrm{~A}_{35}$ \\
$\ldots$ & $\ldots$ \\
$\mathrm{A}_{60} \rightarrow \#$ & $\mathrm{~A}_{60}$ \\
\hline
\end{tabular}

Tabel 7. FLRG dengan Memperhatikan Pengulangan dan Peramalannya

\begin{tabular}{cc}
\hline $\boldsymbol{F L} \boldsymbol{R} \boldsymbol{G}$ & $\boldsymbol{F}(\boldsymbol{t})$ \\
\hline $\mathrm{A}_{24} \rightarrow \mathrm{A}_{44}$ & $\mathrm{~A}_{44}$ \\
$\mathrm{~A}_{26} \rightarrow \mathrm{A}_{45}$ & $\mathrm{~A}_{45}$ \\
$\mathrm{~A}_{30} \rightarrow \mathrm{A}_{34}$ & $\mathrm{~A}_{34}$ \\
$\mathrm{~A}_{32} \rightarrow \mathrm{A}_{37}, \mathrm{~A}_{34}$ & $\mathrm{~A}_{37}, \mathrm{~A}_{34}$ \\
$\mathrm{~A}_{33} \rightarrow \mathrm{A}_{41}, \mathrm{~A}_{37}, \mathrm{~A}_{41}, \mathrm{~A}_{42}, \mathrm{~A}_{35}$ & $\mathrm{~A}_{41}, \mathrm{~A}_{37}, \mathrm{~A}_{42}, \mathrm{~A}_{35}$ \\
$\ldots$ & $\ldots$ \\
$\mathrm{A}_{60} \rightarrow \#$ & $\mathrm{~A}_{60}$ \\
\hline
\end{tabular}

e) Defuzzifikasi

Proses defuzzifikasi adalah proses untuk menentukan nilai ramalan berdasarkan pada FLR pada Tabel 5 dan FLRG pada Tabel 6 dan Tabel 7. Sebagai contoh, data Januari 2009 memiliki $F L R$ yaitu $A_{35} \rightarrow A_{30}$ dan FLRG yaitu $A_{35} \rightarrow A_{30}$, maka nilai ramalan merupakan nilai tengah $u_{30}$ o yaitu -42500. Defuzzifikasi dilakukan menggunakan algoritma Chen, Yu, Cheng dengan $\alpha=0,9$, dan Lee dengan nilai $c=1,1$. Hasil defuzzifikasi untuk data in-sample dapat dilihat pada Tabel 8 dan untuk data out-sample ditampilkan pada Tabel 9. 
Tabel 8. Hasil Defuzzifikasi untuk Data In-Sample

\begin{tabular}{ccccccc}
\hline \multirow{2}{*}{ Tahun } & \multirow{2}{*}{ Bulan } & \multirow{2}{*}{\begin{tabular}{c} 
Residu dari \\
\cline { 4 - 7 }
\end{tabular}} & & \multicolumn{5}{c}{ Model SSA } & Chen & Yu & $\begin{array}{c}\text { Cheng } \\
(\boldsymbol{\alpha}=\mathbf{0 , 9})\end{array}$ & $\begin{array}{c}\text { Lee } \\
(\boldsymbol{c}=\mathbf{1 , 1})\end{array}$ \\
\hline 2009 & Jan & -17876.31 & - & - & - & - \\
2009 & Feb & -41543.39 & 1875 & 6944.44 & -1754.5 & 4529.02 \\
2009 & Mar & -20006.57 & -22500 & -22500 & -24404 & -22500 \\
$\ldots$ & $\ldots$ & $\ldots$ & $\ldots$ & $\ldots$ & $\ldots$ & $\ldots$ \\
2018 & Nov & -13095.3 & -4500 & -7733.9 & -2230.8 & -6882.7 \\
2018 & Des & 107399.3 & 25500 & 24722.2 & 11440.5 & 19630.7 \\
\hline
\end{tabular}

Tabel 9. Hasil Defuzzifikasi untuk Data Out-Sample

\begin{tabular}{ccccccc}
\hline \multirow{2}{*}{ Tahun } & \multirow{2}{*}{ Bulan } & \multirow{2}{*}{$\begin{array}{c}\text { Residu dari } \\
\text { Model SSA }\end{array}$} & Chen & Yu & $\begin{array}{c}\text { Cheng } \\
(\boldsymbol{\alpha}=\mathbf{0 , 9 )}\end{array}$ & $\begin{array}{c}\text { Lee } \\
(\boldsymbol{c}=\mathbf{1 , 1})\end{array}$ \\
\hline 2019 & Jan & 58849,99 & - & - & - & - \\
2019 & Feb & $-25534,4$ & 57500 & 57500 & 57635 & 57500 \\
2019 & Mar & -100736 & 1250 & 1166.67 & 596.559 & 2792.05 \\
$\ldots$ & $\ldots .$. & $\ldots$ & $\ldots$ & $\ldots$ & $\ldots$ & $\ldots$ \\
2018 & Nov & $-2700,14$ & -4166.67 & -4587.91 & -3019.79 & -3982.5 \\
2018 & Des & 89719,65 & 9375 & 9871.79 & 3854.99 & 8194.88 \\
\hline
\end{tabular}

3) Menghitung Nilai Ramalan Akhir

Nilai ramalan akhir diperoleh dengan menjumlahkan nilai ramalan SSA dengan $R$-forecasting dan nilai ramalan residu yang diperoleh menggunakan metode WFTS. Nilai ramalan akhir untuk data out-sample ditampilkan pada Tabel 10 dan untuk data in-sample ditampilkan pada Tabel 11.

Tabel 10. Nilai Ramalan Akhir untuk Data In-sample

\begin{tabular}{cccccc}
\hline & & \multicolumn{4}{c}{ Nilai Ramalan Akhir } \\
\cline { 3 - 6 } Tahun & Bulan & $\begin{array}{c}\text { SSA-WFTS } \\
\text { Chen }\end{array}$ & $\begin{array}{c}\text { SSA-WFTS } \\
\text { Yu }\end{array}$ & $\begin{array}{c}\text { SSA-WFTS } \\
\text { Cheng } \\
(\boldsymbol{\alpha}=\mathbf{0 , 9})\end{array}$ & $\begin{array}{c}\text { SSA-WFTS } \\
\text { Lee } \\
(\boldsymbol{c}=\mathbf{1 , 1})\end{array}$ \\
\hline 2009 & Jan & - & - & - & - \\
2009 & Feb & 191122 & 196192 & 187493 & 193776 \\
2009 & Mar & 165712 & 165712 & 163807 & 165712 \\
$\ldots$ & $\ldots$ & $\ldots$ & $\ldots$ & $\ldots$ & $\ldots$ \\
2018 & Nov & 415320 & 412086 & 417589 & 412938 \\
2018 & Des & 416920 & 416142 & 402860 & 411050 \\
\hline
\end{tabular}

Tabel 11. Nilai Ramalan Akhir untuk Data Out-sample

\begin{tabular}{cccccc}
\hline & & \multicolumn{4}{c}{ Nilai Ramalan Akhir } \\
\cline { 3 - 6 } Tahun & Bulan & $\begin{array}{c}\text { SSA }- \text { WFTS } \\
\text { Chen }\end{array}$ & $\begin{array}{c}\text { SSA }- \text { WFTS } \\
\text { Yu }\end{array}$ & $\begin{array}{c}\text { SSA - WFTS } \\
\text { Cheng } \\
(\boldsymbol{\alpha}=\boldsymbol{0 , 9})\end{array}$ & $\begin{array}{c}\text { SSA }- \text { WFTS } \\
\text { Lee } \\
(\boldsymbol{c}=\mathbf{1 , 1})\end{array}$ \\
\hline 2019 & Jan & - & - & - & - \\
2019 & Feb & 520490 & 520490 & 520625 & 520490 \\
2019 & Mar & 551555 & 551472 & 550902 & 553097 \\
$\ldots$ & $\ldots$ & $\ldots$ & $\ldots$ & $\ldots$ & $\ldots$ \\
2019 & Nov & 496458 & 496037 & 497605 & 496643 \\
2019 & Des & 472058 & 472555 & 466538 & 470878 \\
\hline
\end{tabular}

4) Menghitung MAPE dan Menentukan Model Terbaik 
Berdasarkan Tabel 12, metode SSA- WFTS dengan algoritma Chen memiliki nilai MAPE terkecil dibanding metode lainnya untuk data out-sample, yaitu sebesar 9,029\%. Maka dari itu, pemodelan untuk meramalkan jumlah kunjungan wisatawan mancanegara ke Bali menggunakan SSA-WFTS algoritma Chen merupakan model terbaik dibandingkan model SSA R-forecasting, SSA-WFTS algoritma Yu, SSA-WFTS algoritma Cheng $(\alpha=0,9)$, dan SSA-WFTS algoritma Lee $(c=1,1)$.

Tabel 12. Nilai MAPE

\begin{tabular}{ccc}
\hline Data & Metode & MAPE \\
\hline \multirow{4}{*}{ In-sample } & SSA R-forecasting & $5,156 \%$ \\
& SSA-WFTS metode Chen & $5,154 \%$ \\
& SSA-WFTS metode Yu & $5,139 \%$ \\
& SSA-WFTS metode Cheng $(\alpha=0,9)$ & $4,762 \%$ \\
& SSA-WFTS metode Lee $(\mathrm{c}=1,1)$ & $5,057 \%$ \\
\hline Out-sample & SSA R-forecasting & $14,515 \%$ \\
& SSA-WFTS metode Chen & $\mathbf{9 , 0 2 9} \%$ \\
& SSA-WFTS metode Yu & $9,067 \%$ \\
& SSA-WFTS metode Cheng $(\alpha=0,9)$ & $9,125 \%$ \\
& SSA-WFTS metode Lee (c $=1,1)$ & $9,082 \%$ \\
\hline
\end{tabular}

\section{Simpulan}

Berdasarkan analisis yang telah dilakukan, peramalan jumlah kunjungan wisatawan mancanegara ke Bali menggunakan metode hibrida SSA-WFTS diperoleh model terbaik yaitu model SSA-WFTS dengan algoritma Chen. Model SSA-WFTS dengan metode Chen menghasilkan nilai MAPE terkecil yaitu sebesar 9,029\%, dibandingkan dengan model SSA Rforecating, SSA-WFTS metode Yu, SSA-WFTS metode Cheng $(\alpha=0,9)$, dan SSA-WFTS metode Lee $(c=1,1)$.

\section{Daftar Pustaka}

[1] A. Hutauruk and S. Harto, "Pengaruh Kunjungan Wisatawan Asing terhadap Ekonomi Pariwisata Indonesia.," Jurnal Online Mahasiswa Fakultas Ilmu Sosial dan Ilmu Politik Universitas Riau, vol. 4, no. 2, pp. 1-14, 2017.

[2] U. Nations, International Recommendations for Tourism Statistics 2008, New York: United Nations Publication, 2010.

[3] T. A. Secretariat, ASEAN STATISTICAL YEARBOOK 2020, Jakarta: Association of Southeast Asian Nations (ASEAN) 2020, 2020.

[4] L. U. Calderwood and M. Soshkin, "The Travel \& Tourism Competitiveness Report 2019," World Economic Forum's Platform, Geneva, 2019.

[5] B. S. Distribusi, "STATISTIK WISATAWAN MANCANEGARA KE BALI 2018," BPS Provinsi Bali, Despansar, 2019.

[6] N. Golyandina and A. Zhigljavsky, Singular Spectrum Analysis for Time Series, vol. 120, Berlin: Springer, 2013.

[7] H. Khaeri, E. Yulian and G. Darmawan, "Penerapan Metode Singular Spectrum Analysis (SSA) pada Peramalan Jumlah Penumpang Kereta Api di Indonesia Tahun 2017," Jurnal Euclid, vol. 5, no. 1, pp. 8-19, 2017. 
[8] R. S. K. Siregar, D. Prariesa and G. Darmawan, "Aplikasi Metode Singular Spectral Analysis (SSA) dalam Peramalan Pertumbuhan Ekonomi Indonesia Tahun 2017," Jurnal Matematika "MANTIK", vol. 3, no. 1, pp. 5-12, 2017.

[9] M. Sari, I. W. Sumarjaya and M. Susilawati, "Peramalan Jumlah Kunjungan Wisatawan Mancanegara ke Bali Menggunakan Metode Singular Spectrum Analysis," E-Jurnal Matematika, vol. 8, no. 4, pp. 303-308, 2019.

[10] G. Zhang, "Time series forecasting using a hyrid ARIMA and neural network model," Neurocomputing, vol. 50, pp. 159-175, 2001.

[11] Q. Song and B. Chissom, "Fuzzy time series and its model," Fuzzy Sets and System, vol. 54, no. 3, pp. 269-277, 1993.

[12] S. Chen, "Forecasting enrollments based on fuzzy time series," Fuzzy Sets and System , vol. 81, pp. 311-319, 1996.

[13] H. Yu, "Weighted fuzzy time series models for TAIEX forecasting," Physics A, vol. 349, no. 2, pp. 609-624, 2005.

[14] M. Lee and Suhartono, "A novel weighted fuzzy time series model for forecasting seasonal data," Proceeding the 2nd International Conference on Mathematical Sciences, pp. 332-340, 2010.

[15] W. Sulandari, Subanar, M. Lee and P. Rodrigues, "Indonesia electricity load forecasting using singular spectrum analysis, fuzzy system, and neural networks," Energy, vol. 190, pp. 1-11, 2020.

[16] Subanar and W. Sulandari, "A comparison forecasting methods for trend and seasonal Indonesia tourist arrivals time series," AIP Conference Proceedings, vol. 2329, p. 060012, 2021.

[17] Suhartono and M. H. Lee, "A Hybrid Approach based on Winter's Model and Weighted Fuzzy Time Series for Forecasting Trend and Seasonal Data," Journal of Mathematics and Statistics, pp. 177-183, 2011.

[18] N. Golyandina, V. Nekrutkin and A. Zhigljavsky, Analysis of Time Series Structure:SSA and Related Techniques, Florida: Chapman \& Hall, 2001.

[19] Q. Zhang, B. Wang, B. He, Y. Peng and M. Ren, "Singular Spectrum Analysis and ARIMA Hybrid Model for Annual Runoff Forecasting," Water resources management, vol. 25, no. 11, pp. 2683-2703, 2011.

[20] C. Cheng, T. Chen, H. J. Teoh and C. Chiang, "Fuzzy time-series based on adaptive expectation model for TAIEC forecasting," Expert System with Application, vol. 34, pp. 1126-1132, 2008.

[21] A. A. Ete, M. Fitrianawati and M. T. Arifin, "Forecasting The Number Of Tourist Arrivals To Batam Using The Singular Spectrum Analysis And Arima Methods," Advances in Social Science, Education and Humanities Research, vol. 317, pp. 119-126, 2019. 